\title{
Attitudes of Student Nurses' towards Adherence to Standard Precautions in the Clinical Area at a Large Teaching Hospital in Uganda
}

\author{
Article by Faith R. K. Sebuliba \\ Nursing Department, Uganda Christian University, Mukono, Uganda \\ E-mail: sebulibafaith@gmail.com
}

\begin{abstract}
Standard precautions guidelines are the effective cornerstone W.H.O and CDCC measures of infection control and management used to reduce healthcare associated infections among healthcare workers and patients. However, healthcare workers especially students do not always adhere to them. The purpose of this study was to assess attitudes of student nurses and midwives towards adhering to standard precautions. A quantitative, exploratory study using a self-report questionnaire was carried out on 53 third year diploma nursing and midwifery students at a large teaching hospital in Uganda. Only $81 \%$ of the respondents scored at least $80 \%$ on the attitude scale that was measured using constructs from Rosenstock's, (1974) Health Belief Model. The construct of perceived benefits (84.9\%), self-efficacy (63.5\%), and perceived barriers (62.3\%) rated higher than the rest. The attitudes towards adherence to standard precautions was lower than expected, revealing a gap that may lead to nonadherence to SP and continued predisposition to nosocomial infections in the hospital setting. Findings had implications for nurse educators, administrators, and practitioners to promote nurse's attitudes towards adherence to standard precautions.
\end{abstract}

Keywords: Standard precautions, universal precautions, occupational risks, nosocomial infections, compliance, adherence, health belief model, nurses, healthcare workers.

\section{Introduction}

Standard precautions (SP) are recognized as a cornerstone of effective infection control and management measures that have been demonstrated as effective in reducing healthcare associated infections among patients and healthcare workers. They are the standardized procedures that reduce the risk for exposure to all recognized and unrecognized sources of infection in the hospital (WHO, 2007) and fundamental behaviors expected of all healthcare workers to protect themselves, their patients, and society against the transmission of nosocomial infections. Hospitals harbor high populations of virulent strains of microorganisms resistant to antibiotics that are often transmitted unknowingly by health workers. To prevent the spread of nosocomial infections, the Center for Disease Prevention and Control (CDC), and its Hospital Infection Control Practices Advisory Committee (HICPAC) in 1996 developed a set of protective behaviors, the standard precautions. The SP comprises of measures to guide hand hygiene, use of protective gear, prevention of needle stick injuries, environmental control, prevention of injury from sharp devices, and patient placement (Smeltzer \& Bare, 2004; Potter \& Perry, 2005). WHO, (2007) recommend their use as the minimum level of precautions to be taken when providing care for all patients. The SP's have since been adopted by Ministry of Health in Uganda for use in all health units to help maintain an aseptic field and prevent cross-contamination between the healthcare providers, healthcare providers and patients, and between patients. In addition to reducing the risk of spreading nosocomial infections, SP are designed to protect healthcare workers from occupational hazards like accidental injuries such from sharp instruments.

Nurses, especially students in the clinical area, provide direct patient care and in the process, they engage in risky practices that promote the spread of nosocomial infections. They carry out procedures such as clearing surgical equipment; handling soiled surgical dressings; replacing or removing cannulas; rinsing soiled linen; and collecting specimens that are body tissues, fluids, or blood. During such practices, without any form of protection, the tools nurses use may injure, exposing them to blood and body fluids which may 
DOI: $10.21522 / \mathrm{TIJNR} .2015 .03 .02 . A r t 006$

ISSN: $2520-3126$

contain infectious microorganisms such as Human Immunodeficiency Virus (HIV) and hepatitis B (Wilburn, 2004). About one in eight healthcare workers receive a needle stick injury, and American healthcare workers suffer 800,000 to 1 million needle stick injuries annually (NIOSH, 2000), not including the vast numbers that go unreported. There were more than 100,000 needle sticks injuries annually in the United Kingdom (ICN, 2009), and in developing countries, such injuries are not adequately documented, but it probably equals or exceeds that in the industrial world.

Despite the presence of the guidelines in hospitals and health units, nurses, especially students, do not always adhere to them. Several studies have described the adherence to SP as inconsistent or inadequate (Harris \& Nicolai, 2010; Haile, Engeda, \& Abdo, 2017), suboptimal ( Doebbeling et al., 2003; Fawole, Sadoh, Oladimeji, \& Sotiloye, 2006; Jeong, Cho, \& Park, 2008; Sadoh, Amin \& Wehedy, 2009), rare (Jeong, Cho, \& Park, 2008), low (Rubinson, Wu, Haponik, \& Diette, 2005; Luo, He, Zhou, \& Luo, 2010; Haile, Engeda, \& Abdo, 2017), and unsatisfactory (Lymer, Richt, \& Isaksson, 2004). Professionals have been reported to have exposed themselves and their patients to unnecessary risks of infection when they did not wash hands or use gloves to puncture blood vessels (Cirelli, Figueiredo, \& Zem-Mascarenhas, 2007).

\section{Purpose of the study}

The purpose of the study was to assess the attitude of student nurses towards adhering to standard precautions during placement in the clinical area so the knowledge gained would be used to design strategies to improve adherence to SP and promote safety of healthcare workers, their families, and patients.

\section{Literature review}

An attitude is a tendency for an individual to respond positively or negatively towards a situation, and in healthcare, it is has been mostly associated with one's response or reaction towards infection control recommendations (Oliveira, Marziale, Paiva, \& Lopes, 2009). Attitude influence an individual's choice of action and responses to stimuli that may present as a challenge, an incentive, or reward. Attitudes may be affective responses such as how an individual feel about work following frustration from burnout or no perceived benefit from rendering a service. Behaviors too, may express an attitude, for example when nurses do not adhere to standard precautions, and mental processes such as perceptions also demonstrate attitude. Attitudes can be positive or negative, and positive attitudes have been found to influence compliance to infection control measures (Jimmieson et al., 2016). In this study, the attitudinal object is pertaining to practicing a health behavior of adhering to standard precautions. Student nurse's attitudes towards adhering to standard precautions were explored using The Health Belief Model to describe what attitudes influenced adherence.

\section{The health belief model}

This study used the concepts in the HBM that hold that behavior is a function of the individual's sociodemographic characteristics, knowledge, and attitude. The HBM has been used in several studies and considered useful in health care promotion and prevention. It was considered for study based on the understanding that it would help to describe why nurses adhere or not adhere to SP in practice, if they felt by doing so they would prevent the transmission of nosocomial infections to themselves and their patients. The HBM developed by Rosenstock, (1974), was intended to predict which individuals would or would not use preventive measures such as screening for early detection of cancer. Becker modified the model in 1974 to include individual perceptions (perceived susceptibility, and perceived seriousness), modifying factors (demographic, sociopsychological and structural variables), and others likely to affect initiating actions. These constructs were used to explore nurses' behavior as it relates to adhering to SP. See Figure 1 for a schematic representation of the Health Belief Model. 


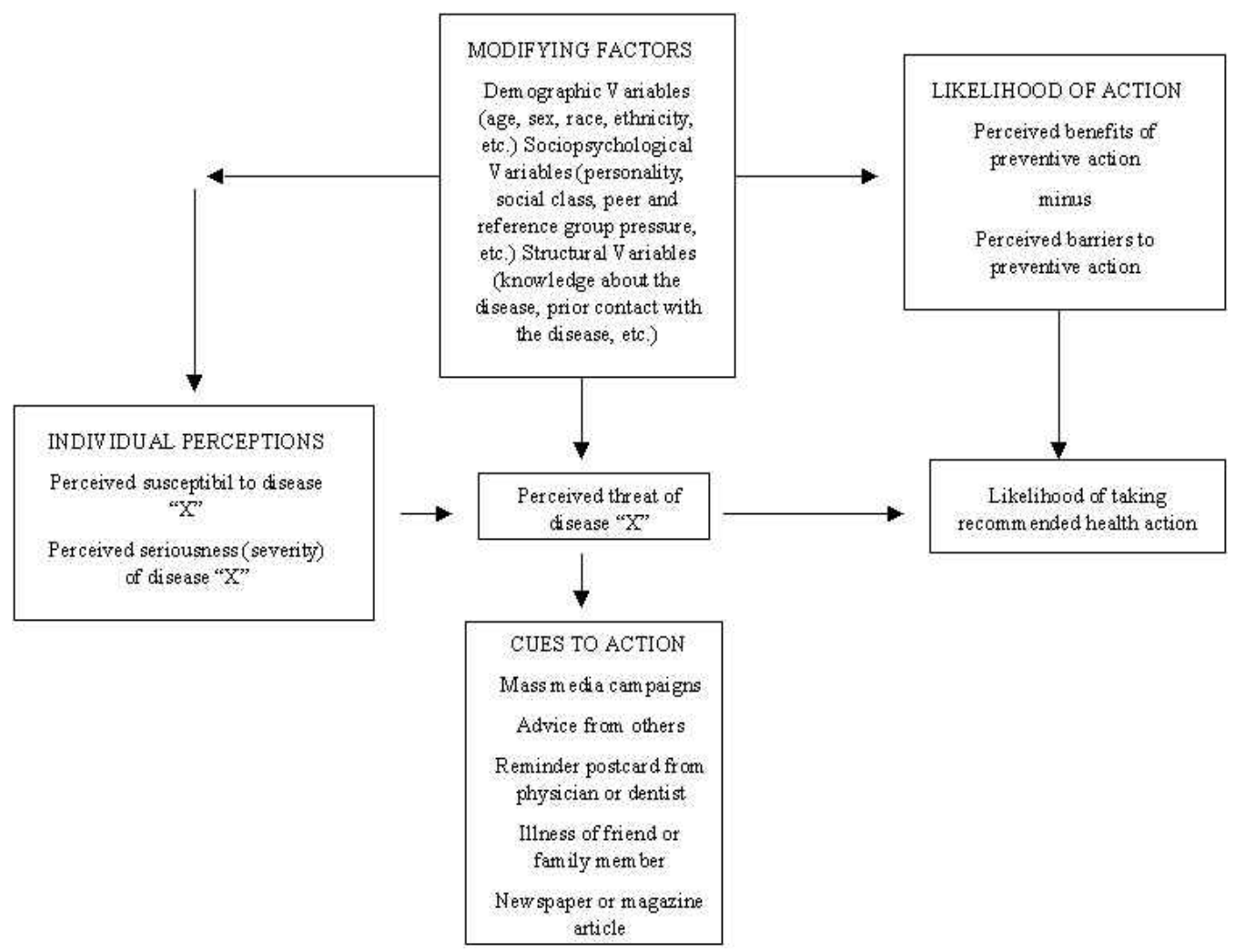

Figure 1. The health belief model (Rosenstock, 1974)

\section{Individual characteristics and experiences}

The HBM holds that each person has unique personal characteristics and experiences that affect subsequent actions (Rosenstock, 1974). These characteristics include prior related behaviors and personal factors that indirectly affect a person's beliefs, affect, and enactment of the health-promoting behavior. The components of the model involve individuals' perceptions of susceptibility to an illness, individuals' perceptions of seriousness of the illness, and likelihood that a person will take a preventive action.

\section{Perceived susceptibility}

Reflects a person's opinion of chances of getting a condition. Nurses work in a hospital environment where they are constantly exposed to risks of contracting infectious diseases. They engage in activities that bring them in direct contact with blood and body fluids that are likely to be infected. Therefore, adhering to SP will prevent them from acquiring or transmitting infections. Studies show that hospital workers perceive a level of susceptibility to acquiring a hospital infection among themselves and their patients, or secondary infection to their family members (Lewis \& Thompson, 2009; Ganczak \& Szych, 2007), and therefore, adhere to the SP because of fear of spreading the infections to their families, patients, and themselves. Other healthcare workers $(\mathrm{HCW})$ revealed fears of contracting infections from work following their engagement in risky behaviors of recapping needles where they sustained needle stick injuries, or working with an abrasion or cut on their hands and were in a situation where the routes for reporting and managing occupational exposures were absent (Reda, Fisseha, Mengistie, \& Vandeweerd, 2010). Healthcare workers in another study perceived an increase in; infections for all, use of antibiotics, morbidity and mortality of patients, and extended hospital stay, if they did not take extra precautions to adhere to hand hygiene (Jimmieson et al., 2016). 
DOI: $10.21522 /$ TIJNR.2015.03.02.Art006

ISSN: $2520-3126$

\section{Perceived severity}

This is a person's opinion of the seriousness and consequences of a condition. The concept is based on how much a person knows about the disease and can result in a change of health behavior. Healthcare workers tend to modified their behavior in accordance with their own subjective assessment of patients' likelihood of having bloodborne viral infections (Ferrer et al., 2009; Cutter \& Jordan, 2004). Most professionals, when they were making decisions about the use of protective clothing they were selective in adherence basing on the nationality, lifestyle, sexual orientation, or perceived low risk patient (Jahangiri, Rostamabadi, Hoboubi, Tadayon, \& Soleimani, 2016; Harris \& Nicolai, 2010;Cutter \& Jordan, 2004). Individuals who do not perceive personal risks from a direct action may not fully understand the severity of not engaging in an action-like adhering to SP.

\section{Likelihood of action}

\section{Perceived benefits}

Perceived benefits are beliefs of individuals in the value of adhering to health-related measures to prevent or reduce the illness or disease. Anticipated benefits or outcomes affect the person's plan to participate in health-promoting behaviors and may facilitate continued practices. The student nurses will use SP during practice when they believe that the measures prescribed will protect them from acquiring infections. Studies have found those nurses who perceived benefit of protection and their family from contracting infections were more likely to adhere to SP (Efstathiou, Papastavrou, Raftopoulos, \& Merkouris, 2011). For example nurses who participated in an education program to improve hand hygiene in a neonatal unit adhered to SP that led to the reduction in bloodstream infections in the neonates (Helder, Brug, Looman, Goudoever, \& Kornelisse, 2010; Chhapola \& Brar, 2015). Other perceived benefits include improvement in hand hygiene (Picheansathian, Pearson, \& Suchaxaya, 2008; Oh, Hamzah, Yan, \& Ang, 2012), and reduction in needle stick injuries.

\section{Perceived barriers}

These are factors that may constrain commitment to action and mediate behavior. The perceived barriers either imagined or real reflect a person's perception about available time, inconvenience, expense, and difficulty performing an activity (Kozier, Erb, Berman \& Snyder, 2004, p. 124). For example, in emergency situations, pausing to follow SP would put the life of a patient at risk (Ferguson, Waitzkin, Beekmann, \& Doebbeling, 2004), or interfere with difficult patient situations when direct care may be required to provide optimal care. Factors such as limited time, type of clinical procedure, irregular education on SP, and nurses' limited involvement in the policy-making process have also been found to contribute to non-adherence to SP (Barrett \& Randle, 2008; Jeong et al., 2008). Similarly, busyness, forgetfulness, and perceptions of skin irritation, inconvenience, poor role modeling, lack of monitoring and feedback have been found to cause barrier to hand hygiene (Foote \& El-Masri, 2016; Pedersen et al., 2017), and non-availability of equipment (Amoran \& Onwube, 2013).

\section{Modifying factors}

Modifying factors are pre-requisite factors whose presence enable an individual to engage in a health behavior and whose absence deter the desired behavior (Kalua \& Nyasulu, 2007). Peers and healthcare providers have been found to be important modifying factors who can increase or decrease commitment to engagement in health-promoting behavior. For example, in-charge nurses who are role models and interested in safety questions, or those who search for and share knowledge about infection control were describes as a great motivation to their peers (Lymer et al., 2004; Foote \& El-Masri, 2016). The location of the hospital, type of unit and number of clinical placements is another modifying factor to adherence to SP (Foote \& El-Masri, 2016). Nurses working in municipal hospitals were more compliant than those in academic hospitals (Ganczak \& Szych, 2007), while those who worked in critical care areas like intensive care units, operating room, or emergency departments, were less likely to consistently adhere to SP as 
compared to those working in the laboratory (Doebbeling et al., 2003).

\section{Cues to action}

Cues to action are the things that may heighten awareness or trigger interest in performing a healthrelated activity such as adhering to SP to prevent acquiring or transmitting HAI. The cues may be internal such as knowledge of outcome of nonadherence, or may be external such as display of information on SP and other infection control measures. Hospitals recommend that guidelines be displayed in places where all care providers can easily access them. Organizational factors such as provision of protective equipment, safety guidelines and occupational characteristics such as frequency of educational programs regarding SP are associated with consistency with adherence to SP (Vaughan et al., 2004). Greater levels of management support such as regular check-ups and supervision were associated with more consistent adherence, whereas negative feedback and increased job demand were associated with a lower likelihood of consistent adherence (Lymer et al., 2004). Increased rates of non-adherence are reported in units where staff do not access guidelines (Maja \& Motshudi, 2009). Prior positive experiences motivate students such as knowledge and display of SP at the places of work, and by observing others engaged in the behavior such as washing hands before and after patient contact.

Although standard precautions are evidence-based measures recommended by CDC/WHO to promote safe practice by preventing spread of HAI, several factors have been found to affect adherence of health care workers to SP. Among those identified, none describes what healthcare worker's attitudes have towards adhering to standard precautions, especially nurses. Adherence to SP is a simple and inexpensive measure used to reduce risk of transmission of infection (Kelcíkova, Skodova, \& Straka, 2011), yet studies show healthcare workers do not always adhere to them. Adherence among student nurses in Uganda has not been studied and may not be different. This study assessed the attitudes of student nurses towards adherence to standard precautions.

\section{Methodology}

\section{Study setting}

The study was carried out at a nursing school that is attached to and uses the large government hospital in Kampala as a clinical area. The hospital models various health promotion projects including infection control. The students receive training conducted at the highest level of professional standards that ensures the nurses exercise professionalism in all their undertakings after they qualify. Given the conditions under which the students' work, the training endeavors to equip them with the skills needed to promote health and prevent devastating consequences resulting from spread of hospital acquired infections.

\section{Design and sampling}

A quantitative, and non-experimental design was carried out to describe what attitudes students had towards adherence to SP. Only 53 third-year nursing and midwifery students who were completing the first or second diploma courses participated in the study, selected by convenience sampling method. The students had worked independently before as staff nurses and used the SP as a measure to prevent spread of infection in the units they worked prior to enrolling in the diploma completion nursing program. At the time of the study, the students had covered a component of infection control and used the measures in their current education program. They had rotated in the medical, surgical, gynecology and obstetrics units for clinical experience where they practiced in the real-world setting the infection prevention measures prescribed in the CDC Standard Guidelines or guidelines by Ministry of Health (MOH) in Uganda.

\section{The questionnaire}

A 30 minute, self-administered questionnaire was distributed to students in the classroom to complete using a self-report approach. It comprised of two sections: a) The demographic data that established information about the respondents, and b) the attitude section that contained statements organized by the 
DOI: $10.21522 /$ TIJNR.2015.03.02.Art006

ISSN: $2520-3126$

constructs of the HBM. The questionnaire was adopted with permission from Lewis \& Thompson, (2009) study to assess clinical employees' perceptions about infection control practices. The tool was considered because of its similarity in the variables under study and the high reliability of the constructs. The Cronbach $\alpha$ for reliability for the subscales in the tool was: perceived severity 0.81 , perceived susceptibility 0.70 , perceived benefits 0.75 , perceived barriers 0.73 , cues to action 0.76 , and self-efficacy 0.65 .

A four-point Likert-type statements related to the recommendations in the SP were used to which the respondents either agreed or disagreed to reflect their attitude towards adherence to SP. Each statement in the constructs was rated, where strongly agreeing with the correct statement or strongly disagreed with a false statement reflected positive attitudes, and a score of 4 points was given. Strongly disagreeing with a correct statement, and strongly agreeing with a false statement scored one point. There were 37 statements and an expected score of 4 points for the most positive response per statement. A total score of $80 \%$ from all constructs was thought to be positive attitude.

\section{Data analysis}

The data from the study were analyzed using quantitative methods. Data was entered twice into Epidata manager software to ensure data integrity and uniformity and exported into SPSS software for analysis. Frequency distribution was run on all data to identify the characteristics and enable description of findings. Tables and graphs were used to present the data. Statistical tests (t-test) was done to establish significant differences between student nurses and midwives attitude towards adhering to SP.

\section{Protection of human subjects}

Permission was sought from the university's Ethical Review Board, and the administration of the nursing training school where the study was conducted. The students volunteered and consented to the study after explaining the nature and benefits.

\section{Results}

\section{Socio-demographic characteristics}

The findings presented were from 53 nursing students, a $94.6 \%$ response rate. The ages of the respondents ranged between 25 and 50 years where the mean and median was 33 and 32 respectively (Figure 2). Most respondents (Table 1) were female (92.5\%). The student midwives were $54.7 \%$ and $45.3 \%$ student nurses. The majority (47.2\%) were attached to the maternity and labor units, $30.2 \%$ medical ward, and the rest combined, were in gynecology, surgical, and other units. Most respondents $(60.0 \%)$ had been in the unit for a period of 1-4 weeks, and the rest had been for longer period of 5-8 weeks (7.6\%) and longer than 9 weeks (26.4\%). Most students had prior working experience ranging between 2 and 27 years, and an average of 8 years, of whom $71.7 \%$ had worked as qualified nurses for a period between 2 and 8 years before joining the present course of study (Figure 3). 


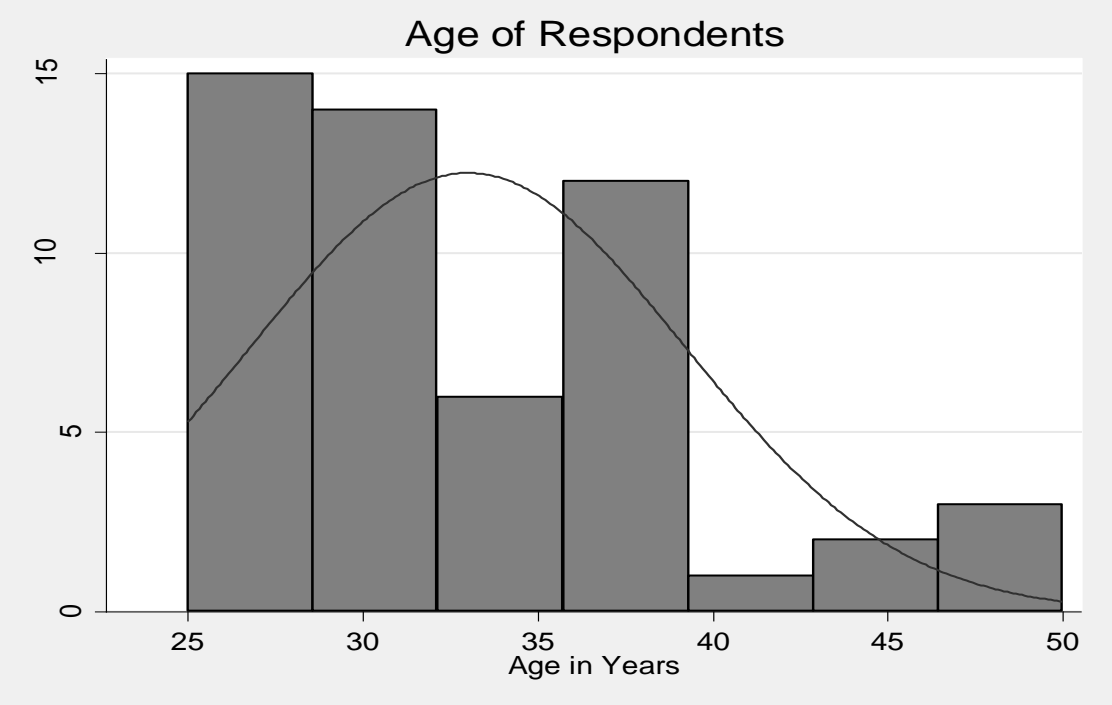

Figure 2: Ages of respondents

Table 1. Socio-demographic characteristics

\begin{tabular}{lll}
\hline Characteristics & Frequency & $\%$ \\
Sex & & \\
Male & 4 & 7.5 \\
Female & 49 & 92.5 \\
\hline Course of study & \\
Nursing & 24 & 45.3 \\
Midwifery & 29 & 54.7 \\
Area of attachment & & \\
Medical & 15 & 30.2 \\
Surgical & 2 & 3.8 \\
Theater & 1 & 1.9 \\
Maternity & 25 & 47.2 \\
Gynecology & 4 & 7.5 \\
Other units & 5 & 9.4 \\
\hline Length of stay in present & & \\
clinical attachment in weeks & & \\
1-4 weeks & 35 & 60.0 \\
5-8 weeks & 4 & 7.6 \\
$>9$ weeks & 14 & 26.4 \\
\hline
\end{tabular}


DOI: $10.21522 /$ TIJNR.2015.03.02.Art006

ISSN: $2520-3126$

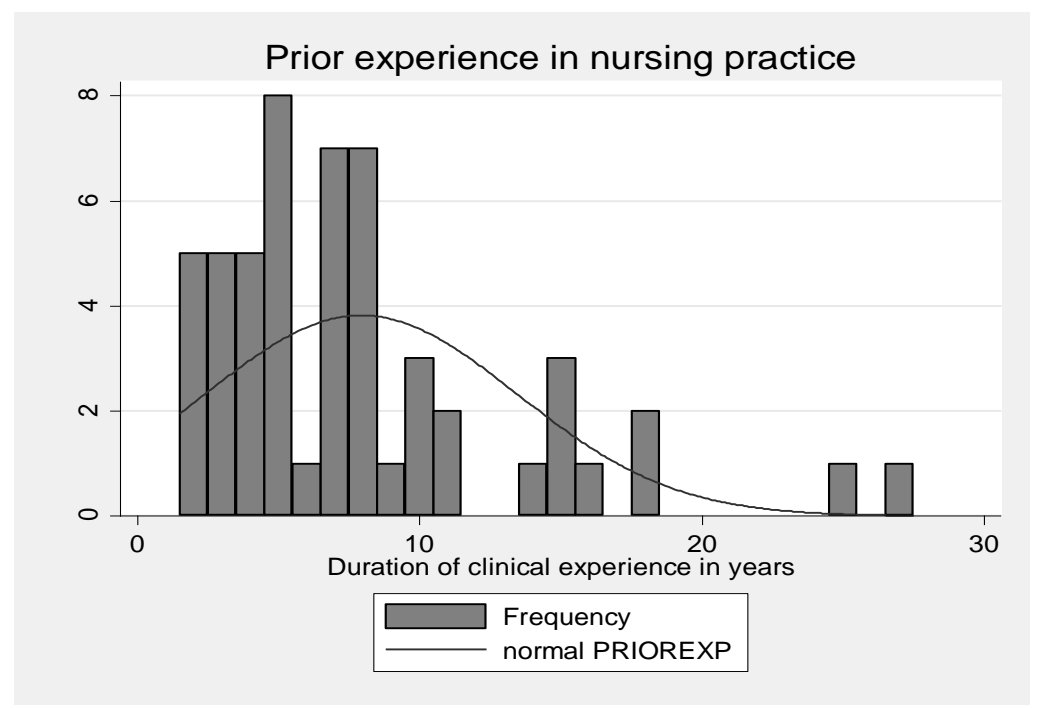

Figure 3. Prior experience before joining course in years

\section{Attitudes}

In this section, Table 2-7 present responses of the nurses regarding their attitude towards adherence to standard precautions as measured per constructs of the HBM. Table 2 and 3 presents the mean, standard deviation, and frequencies of responses for each of the statements in the construct to indicate individual perceptions in the perceived severity and perceived susceptibility respectively.

\section{Individual perceptions}

\section{Perceived severity}

Most respondents in Table 2 strongly agreed or agreed on most of the statements indicating they perceived the severity of acquiring a hospital infection. However, there were some who disagreed to the statement "a patient who obtains a hospital-acquired infection could die (mean 2.60) and "having a patient obtain a hospital acquired infection could cause me trouble" (mean 2.85) indicating these participants may not perceive the severity of acquiring a hospital infection when they did not adhere to SP.

\section{Perceived susceptibility}

In Table 3 respondents agreed with most of the statements on perceived susceptibility to acquiring a hospital infection. Everybody agreed to having infection control as their top concern as healthcare professionals, and most agreed that they could spread infections to their patients if they did not engage in proper infection control (mean 3.64), and they practiced proper infection control because they were concerned for their health and family (mean 3.53). However, most did not perceive the susceptibility of acquiring the hospital infections and disagreed with statement on getting sick with hospital acquired infection all the time. 
Table 2. Perceived severity

\begin{tabular}{|c|c|c|c|c|c|c|}
\hline \multirow[t]{3}{*}{ Perceived Severity Items } & \multirow[t]{3}{*}{ Mean } & \multirow{3}{*}{$\begin{array}{l}\text { Standard } \\
\text { deviation }\end{array}$} & \multicolumn{4}{|c|}{ Frequency of responses } \\
\hline & & & 1 & 2 & 3 & 4 \\
\hline & & & SD & $\mathrm{D}$ & A & SA \\
\hline $\begin{array}{l}\text { 1. Having a patient with a hospital } \\
\text { acquired infection is a very serious } \\
\text { problem for this hospital. }\end{array}$ & 3.06 & 1.027 & 5 & 11 & 13 & 24 \\
\hline $\begin{array}{l}\text { 2. Having a patient with hospital } \\
\text { acquired infection is a very serious } \\
\text { problem for the patient. }\end{array}$ & 3.43 & .636 & 1 & 1 & 25 & 26 \\
\hline $\begin{array}{l}\text { 3. Having a patient with a } \\
\text { hospital-acquired infection is a very } \\
\text { serious problem for me. }\end{array}$ & 3.13 & .761 & 2 & 6 & 28 & 17 \\
\hline $\begin{array}{l}\text { 4. A patient who obtains a } \\
\text { hospital-acquired infection could } \\
\text { die. }\end{array}$ & 2.60 & 1.080 & 11 & 12 & 17 & 13 \\
\hline $\begin{array}{l}\text { 5. Having a patient obtain a } \\
\text { hospital-acquired infection could } \\
\text { cause financial strain for the patient } \\
\text { and the hospital }\end{array}$ & 3.19 & .982 & 6 & 3 & 19 & 25 \\
\hline $\begin{array}{l}\text { 6. Having a patient obtain a } \\
\text { hospital-acquired infection could } \\
\text { cause me trouble }\end{array}$ & 2.85 & .841 & 5 & 8 & 30 & 10 \\
\hline
\end{tabular}

\section{Likelihood of action}

Table 4 and 5 present the means, standard deviation, and frequency of response for each item for the subscales perceived benefits and perceived barriers that demonstrate the individual's likelihood of acting to prevent spread of infection.

\section{Perceived benefits}

For perceived benefits subscale (Table 4), most respondents agreed with all the statements on engaging in infection control measures indicating they perceived the benefits, and only who did not perceive the benefit of health facility saving money (mean 3.49).

\section{Perceived barriers}

The statements to assess perceived barriers in Table 5 were negatively worded to reduce response set among respondents. A respondent who strongly disagreed or disagreed with the statements demonstrated a positive attitude towards engaging in SP practices. Most respondents disagreed with the statements, revealing their likelihood of engaging in infection control measures, while the few who agreed with the statements such as "engaging in proper infection control is expensive" (1.72) and I do not have enough knowledge about infection control" (1.82) perceived the barriers and were likely not to engage in the 
DOI: $10.21522 /$ TIJNR.2015.03.02.Art006

ISSN: $2520-3126$

recommended infection control measures.

Table 3. Perceived susceptibility

Perceived Susceptibility Items

Mean Standard Frequency of responses

deviation

$\begin{array}{llll}1 & 2 & 3 & 4 \\ & \text { D } & \text { A } & \text { SA }\end{array}$

1. If I do not engage in proper infection

3.91

.861

2 control practices, I could spread infection to my family.

2. If I do not engage in proper infection control practices, I could spread infection to my patients.

3. I get sick with

$2.00 \quad .941$

$20 \quad 16$

143

communicable/infectious diseases all the time.

4. Getting a hospital-acquired infection is easy in any health care setting

$\begin{array}{llllll}3.13 & 1.24 & 4 & 10 & 19 & 19\end{array}$

5. Getting a hospital-acquired infection is easy in this health care setting.

6. Infection control is one of my top $3.77 \quad .423$

$0 \quad 0$

12

41 concerns as a health care professional

7. I practice proper infection control because I am concerned for my own health.

8. I practice proper infection control 3.53

3.5

.724

1

4

15

33

because I am concerned for the health of my family. 
Table 4. Perceived benefits

\begin{tabular}{|c|c|c|c|c|c|c|}
\hline \multirow[t]{2}{*}{ Perceived Benefits } & \multirow[t]{2}{*}{ Mean } & \multirow{2}{*}{$\begin{array}{l}\text { Standard } \\
\text { deviation }\end{array}$} & \multicolumn{4}{|c|}{ Frequency of responses } \\
\hline & & & $\begin{array}{l}1 \\
\text { SD }\end{array}$ & $\begin{array}{l}2 \\
\mathrm{D}\end{array}$ & $\begin{array}{l}3 \\
\mathrm{~A}\end{array}$ & $\begin{array}{l}4 \\
\text { SA }\end{array}$ \\
\hline $\begin{array}{l}\text { 1. Engaging in proper infection } \\
\text { control measures protects the health } \\
\text { care provider and the patient. }\end{array}$ & 3.94 & .233 & 0 & 0 & 3 & 50 \\
\hline $\begin{array}{l}\text { 2. Engaging in proper infection } \\
\text { control measures could prevent or } \\
\text { reduce the risk of hospital-acquired } \\
\text { infections. }\end{array}$ & 3.81 & .395 & 0 & 0 & 10 & 43 \\
\hline $\begin{array}{l}\text { 3. Improving my infection control } \\
\text { practices could prevent my patients } \\
\text { from getting hospital-acquired } \\
\text { infections. }\end{array}$ & 3.66 & .586 & 1 & 0 & 15 & 37 \\
\hline $\begin{array}{l}\text { 4. I feel good about myself when I } \\
\text { engage in proper infection control } \\
\text { practices. }\end{array}$ & 3.79 & .863 & 0 & 0 & 16 & 36 \\
\hline $\begin{array}{l}\text { 5. Engaging in proper infection } \\
\text { control measures could save the } \\
\text { health care facility money. }\end{array}$ & 3.49 & .800 & 2 & 4 & 13 & 34 \\
\hline
\end{tabular}

\section{Cues to action}

Most respondents in Table 6 agreed with the statements regarding cues to action notably, "attending professional development seminars on infection control would help them remember to engage in proper infection control activities" (3.36). However, some respondents strongly disagreed with statements "if a poster was in the duty room, I would remember to wash my hands" (mean 2.66) and "if a coworker or infection control practitioner reminded regularly to engage in infection control practices, I would remember" (mean 2.58), revealing that cues may not be enough to remind individuals to engage in infection control measures.

\section{Self-efficacy}

Table 7 show high means (3.02 to 3.75) from the responses indicating the respondents believed their self-efficacy to involve in infection control measures. Most respondents agreed to all statements, notably "my compliance with infection control recommendations can reduce infections" (mean 3.75). However, some disagreed to their behavior making a difference in a patient acquiring infection (mean 3.27), and the effectiveness of the hand sanitizers to control infection (mean 3.02). 
DOI: $10.21522 /$ TIJNR.2015.03.02.Art006

ISSN: $2520-3126$

Table 5. Barriers to action

\begin{tabular}{|c|c|c|c|c|c|c|}
\hline \multirow[t]{3}{*}{ Barrier Items } & \multirow[t]{3}{*}{ Mean } & \multirow{3}{*}{$\begin{array}{l}\text { Standard } \\
\text { deviation }\end{array}$} & \multicolumn{4}{|c|}{ Frequency of responses } \\
\hline & & & 1 & 2 & 3 & 4 \\
\hline & & & SD & D & A & SA \\
\hline $\begin{array}{l}\text { 1. Engaging in proper infection } \\
\text { control practices is expensive. }\end{array}$ & 1.72 & .818 & 26 & 17 & 9 & 1 \\
\hline $\begin{array}{l}\text { 2. I do not feel that I have enough } \\
\text { knowledge about infection control } \\
\text { practices. }\end{array}$ & 1.82 & .709 & 19 & 25 & 9 & 0 \\
\hline $\begin{array}{l}\text { 3. I do not like engaging in proper } \\
\text { infection control practices. }\end{array}$ & 1.32 & .581 & 38 & 14 & 0 & 1 \\
\hline $\begin{array}{l}\text { 4. I do not feel that engaging in } \\
\text { proper infection control practices in } \\
\text { my practice is my responsibility. }\end{array}$ & 1.36 & .736 & 40 & 9 & 2 & 2 \\
\hline $\begin{array}{l}\text { 5. I feel that it takes too much time } \\
\text { to engage in proper infection control } \\
\text { measures. }\end{array}$ & 1.40 & .599 & 35 & 15 & 3 & 0 \\
\hline $\begin{array}{l}\text { 6. I feel that engaging in proper } \\
\text { infection control measures is too } \\
\text { hard. }\end{array}$ & 1.32 & .581 & 38 & 14 & 0 & 1 \\
\hline $\begin{array}{l}\text { 7. Infection control practices } \\
\text { interfere with patient care. }\end{array}$ & 1.34 & .553 & 37 & 14 & 2 & 0 \\
\hline
\end{tabular}

Table 6. Cues to action

\begin{tabular}{|c|c|c|c|c|c|c|}
\hline \multirow[t]{3}{*}{ Cues to Action Items } & \multirow[t]{3}{*}{ Mean } & \multirow{3}{*}{$\begin{array}{l}\text { Standard } \\
\text { deviation }\end{array}$} & \multicolumn{4}{|c|}{ Frequency of responses } \\
\hline & & & 1 & 2 & 3 & 4 \\
\hline & & & SD & $\mathrm{D}$ & A & SA \\
\hline $\begin{array}{l}\text { 1. Taking courses in infection } \\
\text { control could prevent a patient from } \\
\text { getting a hospital-acquired } \\
\text { infection. }\end{array}$ & 3.09 & .904 & 5 & 4 & 25 & 19 \\
\hline $\begin{array}{l}\text { 2. If a poster was present in the } \\
\text { duty room, I would remember to } \\
\text { wash my hands. }\end{array}$ & 2.66 & .999 & 9 & 11 & 22 & 11 \\
\hline
\end{tabular}


Texila International Journal of Nursing

Volume 3, Issue 2, Dec 2017

\begin{tabular}{|c|c|c|c|c|c|c|}
\hline $\begin{array}{l}\text { 3. If a coworker or infection } \\
\text { control practitioner reminded me } \\
\text { regularly to engage in infection } \\
\text { control practices, I would } \\
\text { remember. }\end{array}$ & 2.58 & 1.027 & 10 & 13 & 19 & 11 \\
\hline $\begin{array}{l}\text { 4. Attending professional } \\
\text { development seminars on infection } \\
\text { control would help me remember to } \\
\text { engage in proper infection control } \\
\text { activities. }\end{array}$ & 3.36 & .653 & 0 & 5 & 24 & 24 \\
\hline $\begin{array}{l}\text { 5. Seeing my supervisor wash } \\
\text { hands in between procedures } \\
\text { motivates me to wash mine }\end{array}$ & 3.09 & .766 & 2 & 7 & 28 & 16 \\
\hline
\end{tabular}

Table 7. Self-efficacy

\begin{tabular}{|c|c|c|c|c|c|c|}
\hline \multirow[t]{2}{*}{ Self-Efficacy Items } & \multirow[t]{2}{*}{ Mean } & \multirow{2}{*}{$\begin{array}{l}\text { Standard } \\
\text { deviation }\end{array}$} & \multicolumn{4}{|c|}{ Frequency of responses } \\
\hline & & & $\begin{array}{l}1 \\
\mathrm{SD}\end{array}$ & $\begin{array}{l}2 \\
D\end{array}$ & $\begin{array}{l}3 \\
\mathrm{~A}\end{array}$ & $\begin{array}{l}4 \\
\text { SA }\end{array}$ \\
\hline $\begin{array}{l}\text { 1. My behavior can make a difference } \\
\text { in whether a patient acquires an } \\
\text { infection while hospitalized. }\end{array}$ & 3.27 & .795 & 2 & 5 & 22 & 23 \\
\hline $\begin{array}{l}\text { 2. Information I obtain on infection } \\
\text { control practices can improve patient } \\
\text { care. }\end{array}$ & 3.65 & .590 & 1 & 0 & 15 & 36 \\
\hline $\begin{array}{l}\text { 3. My compliance with infection } \\
\text { control recommendations can reduce } \\
\text { infections. }\end{array}$ & 3.75 & .440 & 0 & 0 & 13 & 38 \\
\hline $\begin{array}{l}\text { 4. I follow infection control } \\
\text { recommendations regularly. }\end{array}$ & 3.17 & .617 & 0 & 6 & 31 & 15 \\
\hline $\begin{array}{l}\text { 5. I often use soap and water to wash } \\
\text { my hands while working in the health } \\
\text { care setting to reduce spread of } \\
\text { infections. }\end{array}$ & 3.38 & .661 & 0 & 5 & 22 & 25 \\
\hline $\begin{array}{l}\text { 6. Hand sanitizers, when available, } \\
\text { are as effective as hand washing in } \\
\text { controlling infection. }\end{array}$ & 3.02 & .804 & 3 & 7 & 28 & 14 \\
\hline
\end{tabular}

\section{Comparison of subscales}

To rate which construct respondents revealed best attitudes towards adhering to SP, the total score for each statement in the subscale were summed and the findings are presented in Table 8. 
DOI: $10.21522 /$ TIJNR.2015.03.02.Art006

ISSN: $2520-3126$

Table 8. Comparison of item score per construct

\begin{tabular}{|c|c|c|c|c|c|c|c|c|c|}
\hline \multicolumn{2}{|c|}{ Subscales } & \multicolumn{8}{|c|}{ Total item score frequency and percent's (\%) } \\
\hline & & 1 & 2 & 3 & 4 & 5 & 6 & 7 & 8 \\
\hline 1. & Severity & 0 & $\begin{array}{l}3 \\
(5.7)\end{array}$ & $\begin{array}{l}10 \\
(18.9)\end{array}$ & $\begin{array}{l}7 \\
(13.2)\end{array}$ & $\begin{array}{l}14 \\
(26.4)\end{array}$ & $\begin{array}{l}19 \\
(35.8)\end{array}$ & - & - \\
\hline 2. & Susceptibility & 0 & 0 & 0 & $\begin{array}{l}1 \\
(1.9)\end{array}$ & $\begin{array}{l}9 \\
(17.0)\end{array}$ & $\begin{array}{l}11 \\
(20.8)\end{array}$ & $\begin{array}{l}24 \\
(45.3)\end{array}$ & $\begin{array}{l}8 \\
(15.1)\end{array}$ \\
\hline 3. & Benefits & 0 & 0 & 0 & $\begin{array}{l}8 \\
15.1\end{array}$ & $\begin{array}{l}45 \\
(84.9)\end{array}$ & - & - & - \\
\hline 4. & Cues & $\begin{array}{l}4 \\
(7.5)\end{array}$ & $\begin{array}{l}8 \\
(15.1)\end{array}$ & $\begin{array}{l}6 \\
(11.3)\end{array}$ & $\begin{array}{l}12 \\
(22.6)\end{array}$ & $\begin{array}{l}23 \\
(43.4)\end{array}$ & - & - & - \\
\hline 5. & Barriers & 0 & 0 & 0 & $\begin{array}{l}1 \\
(1.9)\end{array}$ & $\begin{array}{l}7 \\
(13.2)\end{array}$ & $\begin{array}{l}12 \\
(22.6)\end{array}$ & $\begin{array}{l}33 \\
(62.3)\end{array}$ & - \\
\hline 6. & Self-efficacy & 0 & 0 & $\begin{array}{l}1 \\
(1.9)\end{array}$ & $\begin{array}{l}7 \\
(13.5) \\
\end{array}$ & $\begin{array}{l}11 \\
(21.2) \\
\end{array}$ & $\begin{array}{l}33 \\
(63.5) \\
\end{array}$ & - & - \\
\hline
\end{tabular}

The highest scores (100\%) per construct in Table 8 are as follows: perceived severity $35.8 \%$, perceived susceptibility $15.1 \%$, perceived benefits $84.9 \%$, cues to action $43.4 \%$, perceived barriers $62.3 \%$, and selfefficacy $63.5 \%$, where perceived benefits, self-efficacy, and perceived barriers showed greater percentage. The overall score for the individual participants was summed and a total was categorized into two groups: the score of $80 \%$ and above was rated positive, favorable attitude or acceptable, and $79 \%$ and below was rated not acceptable. Most respondents (81.1\%) scored $80 \%$ and above indicating an acceptable attitude towards adherence to standard precautions (Table 9). An independent $t$-test to determine the mean differences in the nurses and midwives' attitudes showed midwives demonstrated a more acceptable attitude than the nurses, however, it was not statistically significant $(p=.220, t=-.618)$.

Table 9. Total attitude score

\begin{tabular}{llll}
\hline & \multicolumn{3}{l}{ Percentage total attitude score } \\
\cline { 2 - 4 } Course & $<79$ & $>80$ & Total \\
Student nurse & 3 & 21 & 24 \\
Student midwife & 7 & 22 & 27 \\
Total & 10 & 43 & 53 \\
\hline
\end{tabular}

\section{Discussion}

This chapter discusses the findings from the study to assess factors influencing non-adherence to standard precautions (SP) among student nurses and midwives at a large training school in Uganda. This study explored the students' attitudes towards adherence to SP guided by the constructs from The Health Belief Model (HBM) that have been used successfully previously to study human behavior and attitudes including adhering to standard precautions (Osborne, 2003; Lewis \& Thompson, 2009; Efstathiou, Papastavrou, Raftopoulos, \& Merkouris, 2011). The study, despite the perceived barriers, found $81 \%$ of the respondents scored $80 \%$ and above on the attitude scale and concluded the students demonstrated a positive or more acceptable attitude towards adherence to standard precautions.

\section{Attitude}

Attitude of an individual is very important in predicting behavior. The respondents demonstrated an acceptable attitude towards adherence to SP. Respondents agreed with most statements, however, there were some surprises. The constructs of the HBM were useful in identifying the attitudes students had 
towards adhering to SP as has been found in other studies carried out on reasons for non-compliant behavior.

\section{Perceived severity}

Most respondents perceived the severity of acquiring or transmitting the hospital-acquired infections when they did not adhere to SP, however, some did not perceive the seriousness of the problem in the hospital and associated costs and death of patient. This is in agreement with Efstathiou et al., (2011) findings. It is not unusual for nurses to get terrified by the idea or cost of getting infected by a hospital acquired infection and passing it on to family or to be terrified by death. The fear of getting infected make the nurses adhere to SP. In the same way Lewis and Thompson (2009) in a study to assess health professionals' perceptions and knowledge of infection control found that while professionals perceived the severity of acquiring hospital infections, they did not perceive any problems or trouble resulting from a patient obtaining a hospital acquired infection while in their care. Nurses who do not perceive the seriousness of the hospital-acquired infections or those who do not perceive the threat of a patient dying from a hospital infection may not engage in safe practices such as adherence to standard precautions.

\section{Perceived susceptibility}

The respondents perceived the susceptibility to hospital infections to themselves, their patients and family if they did not engage in infection control practices. All agreed infection control was their top concern. The finding corresponds with a study by Efstathiou et al., (2011) where nurses perceived the vulnerability to acquiring hospital infections that led them to take preventive measures such as using protection during patient care. However, there were students who did not perceive the threat, especially those who did not perceive acquiring a communicable or infectious disease, and those who did not perceive how easy it was to acquire infection from the hospital. The finding was like Lewis and Thompson's study in 2009. The healthcare workers perceived the risk of hospital acquired infections but no personal risks. Such individuals who do not perceive personal risks are more likely not to engage in practices recommended to reduce transmission of infection such as adhering to SP.

\section{Perceived benefits}

The respondents perceived the benefits of adhering to SP such as protecting the health care provider and the patient from getting a hospital-acquired infection and preventing or reducing the risk of hospitalacquired infection to themselves, their patients, and families. Understanding the benefits implies that the individual is ready to undertake the health protective behavior such as adhering to SP. Perceived benefits are associated with high rates of compliance. This is in line with earlier studies where occupation health student nurses perceived the benefits of compliance to SP that resulted in reduced rates of needle stick injuries (Maja \& Motshudi, 2009).

\section{Cues to action}

Whereas many respondents were motivated by cues that reminded them to comply with SP, many respondents disagreed or strongly disagreed to remembering to wash hands when an infection control practitioner reminded them or by the regular reminder from poster in the duty room. The finding is like that of Lewis and Thompson (2009). Not adhering despite the presence of cues to motivate action is surprising as individuals may still not adhere. Studies have found cues that influence adherence such as: patient considered high risk, previous exposure, and continuous reminders (Efstathiou et al., 2011). Nurses believed that continuous reminders (cues) about need to implement SP improved compliance. Contrary to the recommendation and hospital policy to display cues, Maja \& Motshudi, (2009), found the guidelines that would provide clues to the students were always kept away in sisters in-charge room. The guidelines were not readily available for students to refer and clarify issues when supervisors and mentors were not available, a factor that may increase nonadherence. 
DOI: $10.21522 / \mathrm{TIJNR} .2015 .03 .02 . A r t 006$

ISSN: $2520-3126$

\section{Perceived barriers}

The respondents identified many factors influencing non-adherence to SP however, non-availability of equipment, inconvenience caused by ineffective equipment, emergency and interference with patient care were the most common among them. Several studies have found similar and more barriers (Osborne, 2003; Ferguson et al., 2004; Jeong et al., 2008; Efstathiou et al., 2011). For example, equipment not being available to order; supplies that are rationed or stored away to keep costs low; or equipment available but not of right size or types required; and emergency situations as of life or death where the nurses ration their time to provide care instead of taking time to use protective equipment (Efstathiou et al., 2011). Other healthcare workers perceived barriers such as the expense of engaging in infection control practices. Despite the perceived barriers, most students' attitude towards engaging in infection control practices remained acceptable at $85.7 \%$ and above. This finding shows a more acceptable attitude of the respondents than Lewis and Thompson (2009) finding.

Perceived barriers may contribute to non-adherence but it should be kept in mind that change to adopt new behaviors is not something that comes easily for some individuals. Studies have shown that respondents disclosed that when nurses gain experience they become confident about their capabilities and may not perceive risks (Efstathiou et al., 2011). Feeling confident may not be considered a barrier but resistant to change. Osborne, (2003) found older nurses more resistant to adopting new ways of working which would make them unlikely to adopt new ways of practice such as adhering to recommended guidelines.

\section{Self-efficacy}

The finding show high self-efficacy among respondents suggesting their confidence and readiness to engage in infection control practices. This finding is better than Efstathiou et al., (2011) where nurses in the study disclosed a difficulty to change behavior, even though they knew what they were doing was not correct. This suggests a lack of self-efficacy to engage in infection control practices due to the difficulty in changing behavior.

\section{Limitations}

The study sample comprised of only 53 student nurses and midwives on diploma completion program at a large training school in Uganda. The sample represented only $13.8 \%$ of the student population in the school, and the time for study did not allow to access the entire population of the students. Secondly, a selfreport questionnaire other than an observation study was used to generate subjective views. There was likely to be a tendency to overestimate what an individual knows subjecting findings to bias.

\section{Conclusions}

It emerged from the study that the students demonstrated an acceptable attitude towards adherence to SP. The scores on the measured attitudes using the constructs from The Health Belief Model were found to be higher than $80 \%$ for most students, but fell less than the expected $100 \%$. The student midwives demonstrated more acceptable attitude than the student nurses, although the differences were not statistically significant. The attitudes of the students may therefore, not be the factor that influence nonadherence to SP, but other variables not included in the study. A conclusion was arrived at, that certain conditions may have led to non-adherence to SP other than attitudes.

\section{Recommendations}

There was a gap in the student nurses and midwives' attitudes towards adhering to standard precautions that nurse educators need to address. In planning for the educational needs for students, educators should endeavor to plan activities that increase students' attitudes as they relate to the HBM regardless of the construct for the students to maintain acceptable attitudes that promote adherence. In addition, student nurses and midwives should in their training endeavor to know and practice protective measures that are 
intended to prevent illness and promote health such as the standard precautions. Administrators should organize educational seminars, workshops, or in-service training for their staff to constantly update their knowledge on measures to prevent illness and promote health such as the standard precaution guidelines. Ward in-charges should provide support supervision to students and remind them constantly to carry out protective activities such as washing hands whenever health worker-patient contact is anticipated regardless of nurse's attitudes. In-charges should in addition, provide students cues that attract and motivate them to adhere to the expected behaviors.

Further studies should be carried out to identify factors influencing adherence to standard precautions that were not employed in this study. An observation method on adherence to SP to compliment self-report should be considered to validate attitudes towards, and actual practice of adhering to SP. A heterogeneous sample is recommended to strengthen findings that will enable generalization to other healthcare populations.

\section{Summary}

Standard precautions are the standardized procedures that reduce the risk for exposure to all recognized and unrecognized sources of infection in the hospital, and are fundamental behaviors expected of all nurses to protect themselves, their patients and society against the transmission of communicable diseases. Despite their presence, studies on compliance have revealed non-compliance among all health care workers. This study explored the attitudes of student nurses and midwives towards adherence to SP. Fifty-three (53) students responded to a self-report questionnaire organized by the constructs from the HBM, a model that has been used by other researchers to study compliance. The findings of the study revealed an acceptable attitude from the students. The construct of perceived benefits (84.9\%), self-efficacy (63.5\%), and perceived barriers $(62.3 \%)$ rated higher than the rest.

\section{Acknowledgement}

My deepest gratitude to Connie Clark and Karen Drake whose assistance in undertaking this study I treasure and the student who participated.

\section{References}

[1]. Amin, T., \& Wehedy, A. Al. (2009). Healthcare providers ' knowledge of standard precautions at the primary healthcare level in Saudi Arabia. Healthcare Infection, 14, 65-72. http://doi.org/10.1071/HI09107.

[2]. Amoran, O., \& Onwube, O. (2013). Infection control and practice of standard precautions among healthcare workers in northern Nigeria. Journal of Global Infectious Diseases, 5(4), 156. http://doi.org/10.4103/0974777X.122010.

[3]. Barrett, R., \& Randle, J. (2008). Hand hygiene practices : nursing students ' perceptions. Journal of Clinical Nursing, 17, 1851-1857. http://doi.org/10.1111/j.1365-2702.2007.02215.x.

[4]. Chhapola, V., \& Brar, R. (2015). Impact of an educational intervention on hand hygiene compliance and infection rate in a developing country neonatal intensive care unit. International Journal of Nursing Practice, 21, 486-492. http://doi.org/10.1111/ijn.12283.

[5]. Cirelli, M. A., Figueiredo, R. M. de, \& Zem-Mascarenhas, S. helena. (2007). Adherence to standard precaution in the peripheral vascular access 1. Rev Latino-Am Enfermagem, 15(3), 512-514. Retrieved from www.scielo.br/pdf/rlae/v15n3/v15n3a24.

[6]. Cutter, J., \& Jordan, S. (2004). Uptake of guidelines to avoid and report exposure to blood and body fluids. Journal of Advanced Nursing, 46, 441-452.

[7]. Doebbeling, B. N., Vaughn, T. E., Mccoy, K. D., Beekmann, S. E., Woolson, R. F., Ferguson, K. J., \& Torner, J. C. (2003). Percutaneous injury, blood exposure, and adherence to standard precautions : Are hospital-based health care providers still at risk ? Clinical Infectious Diseases, 37, 1006-1013.

[8]. Efstathiou, G., Papastavrou, E., Raftopoulos, V., \& Merkouris, A. (2011). Factors influencing nurses ' compliance with standard precautions in order to avoid occupational exposure to microorganisms: A focus group study. BMC Nursing, 10(1), 1-12. Retrieved from http://www.biomedcentral.com/1472-6955/10/1. 
DOI: $10.21522 /$ TIJNR.2015.03.02.Art006

ISSN: $2520-3126$

[9]. Ferguson, K. J., Waitzkin, H., Beekmann, S. E., \& Doebbeling, B. N. (2004). Critical incidents of nonadherence with standard precautions guidelines among Community Hospital-based health care workers. Journal of General Internal Medicine, 19(7), 726-731. http://doi.org/10.1111/j.1525.1497.2004.20424.x.

[10]. Ferrer, L. M., Cianelli, R., Norr, K. F., Cabieses, B., Araya, A., Irarra, L., \& Bernales, M. (2009). Observed use of standard precautions in Chilean community clinics. Public Health Nursing, 26(5), 440-448. http://doi.org/10.1111/j.1525-1446.2009.00802.x.

[11]. Foote, A., \& El-Masri, M. (2016). Self-perceived hand hygiene practices among undergraduate nursing students. Journal of Rsearch in Nursing, 21(1), 8-19. http://doi.org/10.1177/1744987115606959.

[12]. Ganczak, M., \& Szych, Z. (2007). Surgical nurses and compliance with personal protective equipment. Journal of Hospital Infection, 66(4), 346-351. http://doi.org/10.1016/j.jhin.2007.05.007.

[13]. Haile, T. G., Engeda, E. H., \& Abdo, A. A. (2017). Compliance with standard precautions and associated factors among healthcare workers in Gondar University Comprehensive Specialized Hospital , Northwest Ethiopia. Journal of Environmental and Public Health, 2017, 1-9. http://doi.org/10.1155/2017/2050635.

[14]. Harris, S. A., \& Nicolai, L. A. (2010). Occupational exposures in emergency medical service providers and knowledge of and compliance with universal precautions. American Journal of Infection Control, 38(2), 86-94. http://doi.org/10.1016/j.ajic.2009.05.012.

[15]. Helder, O. K., Brug, J., Looman, C. W. N., Goudoever, J. B. Van, \& Kornelisse, R. F. (2010). The impact of an education program on hand hygiene compliance and nosocomial infection incidence in an urban neonatal intensive care unit : An intervention study with before and after comparison. International Journal of Nursing Studies, 47, 12451252. http://doi.org/10.1016/j.ijnurstu.2010.03.005.

[16]. Jahangiri, M., Rostamabadi, A., Hoboubi, N., Tadayon, N., \& Soleimani, A. (2016). Needle stick injuries and their related safety measures among nurses in a University Hospital, Shiraz, Iran. Safety and Health at Work, 7(1), 72-77. http://doi.org/10.1016/j.shaw.2015.07.006.

[17]. Jeong, I., Cho, J., \& Park, S. (2008). Compliance with standard precautions among operating room nurses in South Korea. American Journal of Infection Control, 36(10), 739-742. http://doi.org/10.1016/j.ajic.2008.04.253.

[18]. Jimmieson, N. L., Tucker, M. K., White, K. M., Liao, J., Campbell, M., Brain, D., ... Graves, N. (2016). The role of time pressure and different psychological safety climate referents in the prediction of nurses ' hand hygiene compliance. Safety Science, 82, 29-43. http://doi.org/10.1016/j.ssci.2015.08.015.

[19]. Kalua, F., \& Nyasulu, Y. (2007). A review of the role of modifying factors in health education programmes. Malawi Medical Journal, 19(1), 30-31. Retrieved from http://www.pubmedcentral.nih.gov/articlerender.fcgi?artid=3615310\&tool=pmcentrez\&rendertype=abstract $\% 5 \mathrm{Cn}$ http://www.ncbi.nlm.nih.gov/pubmed/23878630\%5Cn

http://www.pubmedcentral.nih.gov/articlerender.fcgi?artid=PMC3615310.

[20]. Kelcíkova, S., Skodova, Z., \& Straka, S. (2011). Effectiveness of hand hygiene education in a basic nursing school curricula. Public Health Nursing, 29(2), 152-159. http://doi.org/10.1111/j.1525-1446.2011.00985.x.

[21]. Lewis, K. L., \& Thompson, J. M. (2009). Health care professionals ' perceptions and knowledge of infection control practices in a community hospital. The Health Care Manager, 28(3), 230-239.

[22]. Luo, Y., He, G., Zhou, J., \& Luo, Y. (2010). Factors impacting compliance with standard precautions in nursing , China. International Journal of Infectious Diseases, 14(12), e1106-e1114. http://doi.org/10.1016/j.jiid.2009.03.037. [23]. Lymer, U., Richt, B., \& Isaksson, B. (2004). Blood exposure: Factors promoting health care workers ' compliance with guidelines in connection with risk. Journal of Clinical Nursing, 13, 547-554.

[24]. Maja, T., \& Motshudi, M. J. (2009). Precautions used by occupational health nursing students during clinical placements. Curationis, 32(1), 14-20.

[25]. NIOSH. (2000). ICN on Preventing needlestick injuries. Retrieved from www.who.int/occupational_health/activities/2icnneed.

[26]. Oh, E., Hamzah, H. B. M., Yan, C. C., \& Ang, E. (2012). Enhancing hand hygiene in a polyclinic in Singapore. International Journal of Evidence-Based Healthcare, 10, 204-210. http://doi.org/10.1111/j.1744-1609.2012.00277.x.

[27]. Oliveira, A. C., Marziale, M. H. P., Paiva, M. H. R. S., \& Lopes, A. C. S. (2009). Knowledge and attitude regarding standard precautions in a Brazilian public emergency service: A cross-sectional study. Rev Esc Enferm 


\section{Texila International Journal of Nursing}

Volume 3, Issue 2, Dec 2017

USP, 43(2), 313-319. Retrieved from www.ee.usp.br/reeusp/.

[28]. Osborne, S. (2003). Influences on compliance with standard precautions among operating room nurses. American Journal of Infection Control, 31(7), 415-423. http://doi.org/10.1067/mic.2003.68.

[29]. Pedersen, L., Elgin, K., Peace, B., Masroor, N., Doll, M., Sanogo, K., .. Bearman, G. (2017). Barriers , perceptions, and adherence: Hand hygiene in the operating room and endoscopy suite. AJIC: American Journal of Infection Control, 45(6), 695-697. http://doi.org/10.1016/j.ajic.2017.01.003.

[30]. Picheansathian, W., Pearson, A., \& Suchaxaya, P. (2008). The effectiveness of a promotion programme on hand hygiene compliance and nosocomial infections in a neonatal intensive care unit. International Journal of Nursing Practice, 14, 315-321. http://doi.org/10.1111/j.1440-172X.2008.00699.x

[31]. Polit, D. F., \& Beck, C. T. (2008). Nursing research, generating and assessing evidence for nursing practice (8th ed.). Philadelphia, PA. Lippincott Williams \& Wilkins.

[32]. Potter, P., \& Perry, A.G., (2005). Fundamentals of nursing (6th ed.). St Louis: Mosby.

[33]. Reda, A. A., Fisseha, S., Mengistie, B., \& Vandeweerd, J. (2010). Standard precautions : Occupational exposure and behavior of health care workers in Ethiopia. PLoS ONE, 5(12), 1-6. http://doi.org/10.1371/journal.pone.0014420. [34]. Rosenstock, I. M. (1974). Historical origins of The Health Belief Model. Health Education \& Behavior, 2(4), 328-335. http://doi.org/10.1177/109019817400200403.

[35]. Rubinson, L., Wu, A. W., Haponik, E. F., \& Diette, G. B. (2005). Why is it internists do not follow guidelines for preventing intravascular catheter infections? Infection Control and Hospital Epidemiology, 26(6), 525-533. Retrieved from https://pdfs.semanticscholar.org/5ca2/34cf7ac919b536c1a8a0684c465ea017213a.

[36]. Smeltzer, S. C., \& Bare, B. G., (2004). Brunner and Suddarth's textbook of medical-surgical nursing (10th ed). Philadelphia, PA: Lippincott Williams \& Wilkin.

[37]. WHO. (2007). Standard precautions in health care key elements at a glance (No. CH-1211). Infection Control. Geneva. Retrieved from http://www.who.int/injection_safety/sign/en/.

[38]. Wilburn, S. Q. (2004). Needlestick and sharps injury prevention. The Online Journal of Issues in Nursing, 9(3), $1-10$. Retrieved from.

http://www.nursingworld.org/MainMenuCategories/ANAMarketplace/ANAPeriodicals/OJIN/TableofContents/Volu me92004/No3Sept04/InjuryPrevention.html. 